\title{
EFEITO DA INCLUSÃO DE FARELO DE ARROZ INTEGRAL EM RAÇÕES PARA LEITÕES DE 21 A 42 DIAS DE IDADE
}

\author{
EFFECT OF INCLUSION OF RICE BRAN IN DIETS FOR PIGLETS FROM \\ 21 TO 42 DAYS OF AGE
}

\author{
Gomes, T.R. ${ }^{1 *}$, Carvalho, L.E. de ${ }^{2 A}$, Freitas, E.R. ${ }^{2 B}$, Nepomuceno, R.C. ${ }^{1}$, Ellery, E.A.C. ${ }^{1}$ \\ e Rufino, R.H.M. ${ }^{1}$
}

1'Departamento de Zootecnia. Centro de Ciências Agrárias. Universidade Federal do Ceará. Fortaleza, CE. Brasil. *thalleszoo@yahoo.com.br

²Departamento de Zootecnia. CCA/UFC. Fortaleza, CE. Brasil. Aeuquerio@ufc.br; Bednardo@ufc.br

\section{PalaVRas chaVe ADICIONAIS}

Alimento alternativo. Desempenho zootécnico. Subproduto do arroz. Suíno.

\section{RESUMO}

Foram utilizados 60 leitões fêmeas e machos castrados, de linhagem comercial, desmamados com média de 21 dias de idade e com peso vivo médio de $5,4 \pm 1,44 \mathrm{~kg}$, com o objetivo de avaliar os efeitos da inclusão de farelo de arroz integral (FAl) em rações para leitões na fase de creche, sobre o desempenho zootécnico, ocorrência de diarréia, bem como a viabilidade econômica. O delineamento experimental utilizado foi inteiramente casualizado com cinco tratamentos $(0,0 ; 5,0 ; 10,0$; 15,0 e $20,0 \%$ de $\mathrm{FAl}$ ) e seis repetições por tratamento, sendo a unidade experimental (parcela) constituída por dois animais. Os resultados mostraram que o consumo de ração médio diário (CRMD), ganho de peso médio diário (GPMD) e conversão alimentar (CA), bem como a ocorrência de diarréia não diferiram significativamente $(p>0,05)$ para os diferentes níveis de inclusão de FAI. A análise econômica mostrou que não houve diferença significativa entre os tratamentos. Concluiu-se que o fornecimento de farelo de arroz integral foi viável até o nível de $20 \%$ de inclusão nas dietas de leitões no período de 21 a 42 dias de idade.

\section{SUMMARY}

Sixty castrated male and female piglets (commercial lineage), weaned at 21 days of age and average live weight of $5.4 \pm 1.44 \mathrm{~kg}$, were

Recibido: 15-12-10. Aceptado: 22-9-11.

\section{AdDitional KEYWORDS}

Alternative feedstuff. Zootechnical performance. Rice by-product. Swine.

used aiming to evaluate the effect on productive performance, diarrhea, and economic viability of adding different levels of rice bran (RB) in rations for pigs. The experimental design was completely randomized with five treatments $(0.0,5.0,10.0$, 15,0 and $20.0 \%$ of RB) and 6 replicates per treatment, where the experimental unit (plot) consisted of two animals. Results showed that daily mean feed intake (DMFI), daily mean weight gain (DMWG) and feed conversion (FC), as well as the occurrence of diarrhea, did not differ significantly $(p>0.05)$ for the different levels of RB inclusion in the ration. The economic analysis showed no significant difference among treatments. It is concluded that adding rice bran up to $20 \%$ in pig ratios for the period from 21 to 42 days of age is technically viable.

\section{INTRODUÇÃO}

O arrozé um dos cereais mais produzidos no mundo e, por ser utilizado principalmente na alimentação humana, apenas os subprodutos do beneficiamento desse grão são utilizados na alimentação animal, com destaque para o farelo integral e a quirera (Lima etal., 2000).

O farelo de arroz integral (FAI) é obtido no polimento do grão de arroz, após o seu 


\section{GOMES, CARVALHO, FREITAS, NEPOMUCENO, ELLERYE RUFINO}

descascamento e que não sofre extração de óleo. Apresenta aspecto farináceo e fibroso, é suave ao tato e representa de $8 \%$ a $11 \%$ do peso total do grão. É constituído da camada intermediária entre a casca e o endosperma, gérmen, fragmentos de arroze pequenas quantidades de casca com granulometria semelhante ao farelo (Luchesi e Justino, 2003).

Conforme os valores tabelados por Rostagno et al. (2005), o FAI é um alimento energético que apresenta energia digestível, metabolizável e líquida para suínos de 3179 , 3111 e $2384 \mathrm{kcal} / \mathrm{kg}$, respectivamente; $89,30 \%$ de matéria seca, $13,24 \%$ de proteína bruta, $14,81 \%$ de gordura, $12,58 \%$ fibra em detergente ácido, 21,30\% fibra em detergente neutro, $0,11 \%$ de cálcio e $0,32 \%$ de fósforo disponível.

Alguns aspectos devem ser considerados para o uso do FAI na alimentação animal. Um deles é que sua composição química pode variar em função do tipo de processamento do arroz, uma vez que não existe uma padronização do método de polimento do grão de arroz durante o seu beneficiamento para o consumo humano (Zardo e Lima, 1999). Segundo Costa (2001), em função do grau de polimento do arroz e da quantidade de casca incorporada ao farelo de arroz, o teor de amido do FAI pode variar de 10 a $20 \%$ e o de fibra bruta 8 a $20 \%$. Outro aspecto importante, é que a sua utilização é limitada devido a efeitos anti-nutricionais, sendo o alto teor de fibra, a presença de fitatos e inibidores enzimáticos e a rancidez oxidativa durante o armazenamento, os mais citados e que podem prejudicar a digestibilidade dos nutrientes da ração (Le Goff, 2002; Selle et al., 2000).

Na literatura não são comuns os relatos do uso de FAI na alimentação de suínos na fase de creche (21 a 63 dias de idade). Por sua vez, os resultados das pesquisas com a utilização desse alimento na ração de suínos com idades mais avançadas têm demonstrado a viabilidade da inclusão em níveis superiores a 30\%. De acordo com Ara et al.
(1975) e Bertol et al. (1990), para suínos em crescimento e terminação, o FAI pode ser usado como substituto de parte ou de todo o milho e parte do farelo de soja resultando em uma inclusão de quase $90 \%$. Já Hurtado Nery et al. (2010), concluiu que a substituição de $100 \%$ do milho por FAI afetou o ganho de peso diário e o peso da carcaça, entretanto a utilização de até $50 \%$ de FAI em substituição ao milho permite obter desempenho zootécnico e características de carcaça similares aos obtidos com rações baseadas em milho para suínos na fase de terminação. Nicolaiewsky et al. (1989) também verificaram que o FAI quando limitado a 30 ou $40 \%$ da ração, possibilitou a obtenção de resultados semelhantes aos obtidos com rações a base de milho. Miyada et al. (1987) trabalhando com suínos em crescimento, não encontraram efeito sobre a conversão alimentar pela substituição do milho pelo FAI até o nível de 50\%. No entanto, Campabadal et al. (1976) observaram redução no ganho de peso diário, a partir do nível de $35 \%$ de FAI na ração de suínos em crescimento e terminação, ao passo que Brooks e Lumanta (1975), trabalhando com suínos na fase de terminação, observaram redução no desempenho a partir do nível de 50\% na ração. Campos et al. (2002), avaliaram o efeito da inclusão de FAI sobre o desempenho e características de carcaças de suínos nas fases de crescimento e terminação e concluíram que os animais que consumiram rações com FAI ao nível de $30 \%$ tiveram pior conversão alimentar e menor ganho de peso quando comparados com os animais do tratamento controle, muito embora essa inclusão não tenha influenciado as características de carcaça. É possível que essas variações se devam entre outros fatores à grande variação na composição química desse subproduto (Lemos e Soares, 1999) e ao tipo de suíno utilizado em cada trabalho por serem épocas distantes.

Diante do exposto os objetivos foram avaliar os efeitos da inclusão do farelo de 
arroz integral em rações para leitões de 21 a 42 dias de idade sobre o desempenho, a ocorrência de diarréia e a viabilidade econômica.

\section{MATERIALE MÉTODOS}

O experimento foi conduzido no Setor de Suinocultura do Departamento de Zootecnia do Centro de Ciências Agrárias da Universidade Federal do Ceará (DZ/CCA/ UFC), situado no Campus do Pici, em Fortaleza, $\mathrm{CE}$, localizado a $03^{\circ} 43^{\prime} 02^{\prime \prime}$ latitude e $38^{\circ}$ $32^{\prime} 35^{\prime \prime}$ longitude, com altitude de 15,49 metros acima do nível do mar. Foram utilizados 60 leitões fêmeas e machos castrados, de linhagem comercial, provenientes do Setor de Suinocultura/UFC, desmamados com média de 21 dias de idade e peso vivo médio de 5,4 $\pm 1,44 \mathrm{~kg}$. O experimento teve duração de 21 dias e foi realizado durante a fase de creche (21 a 42 dias de idade).

Os animais foram distribuídos em cinco tratamentos $(0,0 \% ; 5,0 \% ; 10,0 \% ; 15,0 \%$ e $20,0 \%$ de inclusão de farelo de arroz integral) com seis repetições por tratamento, sendo a unidade experimental (parcela) constituída por dois animais. Devido à uniformidade nos pesos iniciais dos leitões, os mesmos foram distribuídos nos tratamentos seguindo um delineamento inteiramente casualizado.

Os leitões foram alojados em um galpão aberto, construído de alvenaria, pé direito com altura de 2,5 metros, cobertura com telhas de barro e piso compacto de cimento de rugosidade média com declividade em torno de $3 \%$. Cada leitão foi alojado em baia medindo $1,00 \mathrm{~m}$ de largura por $2,00 \mathrm{~m}$ de comprimento, equipada com comedouro de cimento e um bebedouro tipo chupeta, instalados em extremidades opostas. Foram instaladas cortinas de polietileno ao redor de toda extensão do galpão com o intuito de promover um melhor conforto térmico aos leitões após o desmame.

Durante todo o período experimental os dados de temperatura e umidade relativa do ar foram coletados no início da manhã e no final da tarde. As temperaturas foram registradas por termômetros de máxima e mínima e a umidade relativa do ar por meio de termohigrômetro. Os dados de precipitação pluviométrica foram obtidos junto ao Setor de Meteorologia Agrícola do Departamento de Engenharia Agrícola (DENA/CCA/ UFC), situado a 300 metros do galpão experimental.

Para a formulação das rações experimentais (tabela I), foram consideradas as exigências nutricionais recomendadas por Rostagno et al. (2005). As rações experimentais foram formuladas para serem isoprotéicas, isocalóricas, isolisínicas, isocálcicas e isofosfóricas.

Os alimentos foram submetidos a análises bromatológicas no Laboratório de Nutrição Animal (LANA) do Departamento de Zootecnia da Universidade Federal do Ceará, onde se obteve para o farelo de arroz integral (matéria seca: $89,49 \%$ e proteína bruta: $11,46 \%$ ), milho (matéria seca: $88,47 \%$ e proteína bruta: $8,78 \%$ ), farelo de soja (matéria seca: $88,70 \%$ e proteína bruta: $47,10 \%$ ). Os valores de cálcio, fósforo, lisina, metionina, metionina+cistina, fibra bruta FDN, FDA, sódio e gordura foram baseados nas tabelas de Rostagno et al. (2005) e foram corrigidos de acordo com a matéria seca encontrada. As rações na forma farelada e água foram administradas à vontade.

Os dados referentes ao ganho de peso médio diário (GPMD) e consumo de ração médio diário (CRMD) foram obtidos por pesagens semanais individuais dos animais e de suas respectivas rações, menos os desperdícios. A partir destes dados, calculou-se a conversão alimentar (CA).

A avaliação da ocorrência de diarréia foi realizada durante os 21 dias do período experimental (21 a 42 dias de idade), onde foi observado se havia ou não diarréia nos leitões diariamente, em cada baia, por um único observador, sempre no mesmo horário, às 8:00 h. A verificação consistiu em obser- 
Tabela I. Composição percentual, nutricional e custos das rações experimentais para leitões na fase de creche (21 aos 42 dias de idade). (Nutritive composition (\%), and costs of the experimental diets for piglets from 21 to 42 days of age).

\begin{tabular}{|c|c|c|c|c|c|}
\hline \multirow[b]{2}{*}{ Ingredientes } & \multicolumn{5}{|c|}{ Níveis de inclusão de farelo de arroz integral (\%) } \\
\hline & 0 & 5 & 10 & 15 & 20 \\
\hline Milho grão & 54,44 & 49,64 & 44,86 & 40,06 & 35,27 \\
\hline Soja farelo & 31,15 & 30,80 & 30,45 & 30,11 & 29,76 \\
\hline Arroz farelo & 0,00 & 5,00 & 10,00 & 15,00 & 20,00 \\
\hline Leite pó desnatado & 5,00 & 5,00 & 5,00 & 5,00 & 5,00 \\
\hline Açúcar & 3,00 & 3,00 & 3,00 & 3,00 & 3,00 \\
\hline Óleo de soja & 2,53 & 2,72 & 2,92 & 3,11 & 3,31 \\
\hline Fosfato mono-bicálcico & 1,56 & 1,50 & 1,44 & 1,39 & 1,33 \\
\hline Calcário & 0,94 & 0,96 & 0,99 & 1,01 & 1,03 \\
\hline Sal comum & 0,48 & 0,48 & 0,44 & 0,44 & 0,43 \\
\hline L-lisina $\mathrm{HCl}$ & 0,40 & 0,39 & 0,37 & 0,36 & 0,35 \\
\hline Supl. mineral e vitamínico* & 0,40 & 0,40 & 0,40 & 0,40 & 0,40 \\
\hline DL-metionina & 0,14 & 0,14 & 0,13 & 0,13 & 0,12 \\
\hline Total & 100,00 & 100,00 & 100,00 & 100,00 & 100,00 \\
\hline \multicolumn{6}{|l|}{ Níveis nutricionais calculados** } \\
\hline Energia metabolizável (kcal/kg) & 3325,00 & 3325,00 & 3325,00 & 3325,00 & 3325,00 \\
\hline Energia líquida (kcal/kg) & 2452,30 & 2452,20 & 2452,00 & 2451,90 & 2451,70 \\
\hline Proteína bruta (\%) & 21,00 & 21,00 & 21,00 & 21,00 & 21,00 \\
\hline Fibra bruta (\%) & 2,63 & 2,92 & 3,21 & 3,50 & 3,79 \\
\hline FDN (\%) & 10,71 & 11,09 & 11,47 & 11,84 & 12,22 \\
\hline FDA (\%) & 4,47 & 4,58 & 4,69 & 4,80 & 4,91 \\
\hline Lisina total (\%) & 1,45 & 1,45 & 1,45 & 1,45 & 1,45 \\
\hline Metionina total (\%) & 0,59 & 0,59 & 0,59 & 0,59 & 0,59 \\
\hline Metionina + cistina total (\%) & 0,79 & 0,79 & 0,79 & 0,79 & 0,79 \\
\hline Cálcio (\%) & 0,82 & 0,82 & 0,82 & 0,82 & 0,82 \\
\hline Fósforo disponível (\%) & 0,45 & 0,45 & 0,45 & 0,45 & 0,45 \\
\hline Fósforo total (\%) & 0,63 & 0,69 & 0,75 & 0,80 & 0,86 \\
\hline Sódio (\%) & 0,23 & 0,23 & 0,23 & 0,23 & 0,23 \\
\hline Gordura (\%) & 4,85 & 5,68 & 6,51 & 7,33 & 8,16 \\
\hline Custo do kg de ração $(\mathrm{R} \$)$ & 1,31 & 1,30 & 1,28 & 1,27 & 1,26 \\
\hline
\end{tabular}

*Vitamina A 1500 000,00 UI; Vitamina D3 450 000,00 UI; Vitamina E 7500,00 mg; Vitamina K3 1500,00 Tiamina (Vitamina B1) 250,00 mg, Riboflavina (Vitamina B2) 1300,00 mg, Piridoxina (Vitamina B6) 375,00 mg; Vitamina B12 5000,00 mg, Niacina 7500,00 mg, Pantotenato de cálcio 4500,00 mg, Ácido fólico 150,00 mg, Biotina 22,50 mg, Colina 68000,00 mg, Ferro 12500,00 mg, Cobre 5250,00 mg, Manganês 8750,00 mg, Zinco 26 250,00 mg, lodo 350,00 mg, Selênio 75,00 mg.

**Composição calculada considerando os valores de composição química e de energia metabolizável propostos por Rostagno et al. (2005).

var por aproximadamente 10 minutos os leitões, adotando o procedimento adaptado de Vassalo (1995). Como era difícil flagrar o leitão no momento em que ele estivesse defecando, normalmente observou-se o piso da baia e a região perianal dos animais.

Foi utilizado o escore de fezes atribuindo notas para cada animal, diariamente, de 0 a

Archivos de zootecnia vol. 61, núm. 233, p. 132. 
3, sendo: (0) fezes sólidas, (1) fezes pastosas, (2) fezes líquidas/pastosas e (3) fezes líquidas. Apenas os escores 2 e 3 indicavam ocorrência de diarréia. As observações foram tabuladas e calculou-se a porcentagem de incidência de diarréia com o somatório das vezes em que foi observado os escores 2 e 3 , sobre o total de observações registradas para cada tratamento. De acordo com o modelo proposto por Barbin (2003), foram calculadas as porcentagens médias de ocorrência de diarréia transformadas (MODT) pela função:

$$
y=\operatorname{arcsen} \sqrt{(p / 100)}
$$

onde:

$p=$ valor da média de ocorrência de diarréia em porcentagem

Para verificar a viabilidade econômica da utilização do farelo de arroz integral em rações de leitões na fase de creche, determinou-se inicialmente o custo da ração (CR) por quilograma de peso vivo ganho (Yi), segundo a equação proposta por Bellaver etal.(1985):

$$
Y i=(Q i \times P i) / G i
$$

onde:

Yi= custo da ração por quilograma de peso vivo ganho no i-ésimo tratamento;

$\mathrm{Pi}=$ preço por quilograma da ração utilizada no iésimo tratamento;

Qi= quantidade de ração consumida no i-ésimo tratamento;

$\mathrm{Gi}=$ ganho de peso do i-ésimo tratamento.

Em seguida, foram calculados o índice de eficiência econômica (IEE) e o índice de custo (IC) propostos por Fialho et al. (1992):

$$
\begin{aligned}
& \mathrm{IEE}=(\mathrm{MCei} / \mathrm{CTei}) \times 100 \mathrm{e} \\
& \mathrm{IC}=(\text { CTei/MCei }) \times 100
\end{aligned}
$$

onde:

MCei= Menor custo da ração por quilograma ganho, observado entre tratamentos;

CTei= Custo do tratamento i considerado.
Os valores (preços $/ \mathrm{kg}$ ) dos ingredientes utilizados na elaboração dos custos foram obtidos na região metropolitana de Fortaleza, no mês de abril de 2009, sendo: milho (R\$ $0,53 / \mathrm{US} \$ 0,24)$, farelo de soja (R $\$ 1,06 / \mathrm{US} \$$ $0,48)$, farelo de arroz integral ( R $\$ 0,30 / \mathrm{US} \$$ 0,13 ), leite em pó desnatado (R\$ 9,10/US\$ $4,13)$, açúcar (R \$ 0,90/US\$ 0,40), óleo de soja (R\$2,50/US\$1,13), fosfato mono-bicálcico (R \$ 3,00/US\$1,36), calcário (R \$ 0,15/US\$ $0,07)$, sal comum (R $\$ 0,18 / \mathrm{US} \$ 0,08)$, L-lisina $\mathrm{HCl}(\mathrm{R} \$ 8,00 / \mathrm{US} \$ 3,63)$, DL-metionina (R\$ 20,00/US\$9,09), premix vitamínico-mineral (R\$9,38/US\$4,26).

As análises estatísticas dos dados foram realizadas utilizando-se o software estatístico SAS (2001). Foi realizada a análise de variância e, posteriormente, a análise de regressão na tentativa de se estabelecer o melhor nível de inclusão do farelo de arroz. Também foi realizada a comparação das médias pelo teste de Tukey (5\%).

\section{RESULTADOSEDISCUSSÃO}

A temperatura ambiental média no interior do galpão durante o período experimental foi de $27,5^{\circ} \mathrm{C}$, sendo as médias registradas de temperatura máxima e mínima de $29,9^{\circ} \mathrm{Ce} 25,0^{\circ} \mathrm{C}$, respectivamente. Aumidade relativa do ar foi em média $75 \%$. Também foi registrado nesse período uma precipitação pluviométrica de $267,5 \mathrm{~mm}$ com 17 dias de precipitação.

As temperaturas do ar registradas encontram-se acima da faixa ideal de conforto térmico para leitões desmamados, mantidos em condições de umidade relativa do ar de $75 \%$, que situa-se entre $24,0^{\circ} \mathrm{C}$ e $22,0^{\circ} \mathrm{C}$, todavia dentro dos limites de temperatura crítica superior e inferior, $34,0^{\circ} \mathrm{C}$ e $15,0^{\circ} \mathrm{C}$; respectivamente (Hannas, 1999). Deve-se considerar que a zona de termoneutralidade dos animais está relacionada com um ambiente térmico ideal, onde a diferença entre as temperaturas máximas e mínimas é estreita e, dentro da qual, os animais encontram condições adequadas para 


\section{GOMES, CARVALHO, FREITAS, NEPOMUCENO, ELLERY E RUFINO}

expressar suas melhores características produtivas.

\section{DESEMPENHO ZOOTÉCNICO}

As médias e erro-padrão do consumo de ração médio diário (CRMD), ganho de peso médio diário (GPMD) e conversão alimentar (CA) dos leitões na fase de creche (21 a 42 dias de idade) alimentados com rações contendo diferentes níveis de inclusão de farelo de arroz integral estão apresentados na tabela II.

Na avaliação dos dados de desempenho dos leitões, observou-se na análise de regressão que o aumento da inclusão de farelo de arroz integral (FAI) não influenciou significativamente $(\mathrm{p}>0,05)$ o consumo de ração médio diário, o ganho de peso médio diário e a conversão alimentar e que os resultados obtidos com os diferentes níveis de inclusão de FAI também não diferiram em

Tabela II. Desempenho zootécnico dos leitões na fase de creche (21 aos 42 dias de idade) alimentados com dietas contendo diferentes níveis de inclusão de farelo de arroz integral (média \pm erro padrão da média). (Performance of piglets from 21 to 42 days of age, fed diets containing different levels of inclusion of rice bran (mean \pm standard error)).

\begin{tabular}{lccc}
$\begin{array}{l}\text { Níveis de } \\
\text { inclusão } \\
\text { de FAl }\end{array}$ & $\begin{array}{c}\text { ração médio } \\
\text { diário }(\mathrm{g})\end{array}$ & $\begin{array}{c}\text { Ganho de } \\
\text { peso médio } \\
\text { diário }(\mathrm{g})\end{array}$ & $\begin{array}{c}\text { Conversão } \\
\text { alimentar }\end{array}$ \\
\hline 0 & $371 \pm 2,43$ & $254 \pm 2,63$ & $1,461 \pm 13,61$ \\
5 & $430 \pm 3,62$ & $282 \pm 2,89$ & $1,525 \pm 3,66$ \\
10 & $403 \pm 2,64$ & $267 \pm 2,42$ & $1,509 \pm 7,37$ \\
15 & $381 \pm 1,75$ & $239 \pm 2,43$ & $1,594 \pm 14,75$ \\
20 & $365 \pm 2,92$ & $231 \pm 2,97$ & $1,580 \pm 17,33$ \\
Média geral & $390 \pm 1,19$ & $255 \pm 0,92$ & $1,534 \pm 3,45$ \\
ANOVA & $\mathrm{NS}$ & $\mathrm{NS}$ & $\mathrm{NS}$ \\
Regressão & $\mathrm{NS}$ & $\mathrm{NS}$ & $\mathrm{NS}$ \\
CV (\%) & 17,24 & 25,82 & 19,18 \\
Pr>F & 0,23 & 0,33 & 0,60 \\
\hline
\end{tabular}

FAI: Farelo de arroz integral (\%); CV: Coeficiente de variação; NS: Não significativo $(p>0,05)$ pelo teste $\mathrm{F}$. relação ao grupo controle.

O período após o desmame é considerado um período crítico para os suínos, e fundamental para o seu desenvolvimento posterior. Por isso, muitos cuidados são tomados com a qualidade da ração ofertada nessa fase, visto que o nível de consumo retrata a aceitação do alimento sólido fornecido aos leitões e influencia no ganho de peso. Essa preocupação talvez seja a razão para que nutricionistas tenham receio de utilizar alguns alimentos, principalmente ricos em fibra na composição das rações para essa fase.

Entre os efeitos do aumento da fração fibrosa na alimentação de suínos são comuns os relatos de redução no aproveitamento de nutrientes da ração prejudicando o ganho de peso e a conversão alimentar, podendo ainda haver redução ou aumento no consumo de ração dependendo do nível de fibra presente (Ferreira, 1994). Rações com maiores teores de fibra diminuem a energia digestível, o que resulta em aumento no consumo para suprir a deficiência energética (Ramonet et al., 1999). Segundo Bedford (2000), apesar do aumento da motilidade intestinal que se observa em animais alimentados com alta porcentagem de fibras, isto não se traduz em aumento do consumo associado á uma maior velocidade de passagem do alimento pelo trato gastrointestinal. Ao contrário disso, o consumo de ração pode diminuir com o aumento da fração fibrosa nas rações em decorrência do aumento da viscosidade da digesta, que, por sua vez, pode aumentar o volume ocupado pelo alimento no trato gastrointestinal, mantendo a saciedade física por mais tempo e diminuindo o estímulo do animal em consumir ração (Kyriazakis e Emmans, 1995; Schneeman, 1999) e até mesmo diminuir a velocidade de trânsito da disgesta (Bedford, 2000)

Nesse contexto, considerando que as rações experimentais foram formuladas para serem isonutritivas, um aumento no consumo poderia ser associado a uma redução da

Archivos de zootecnia vol. 61, núm. 233, p. 134. 
disponibilidade de energia para os animais devido aos efeitos negativos da fração fibrosa sobre o aproveitamento dos nutrientes da ração, enquanto, uma redução poderia ocorrer em resposta ao volume ocupado pela digesta no trato gastrintestinal e a redução na taxa de passagem do alimento pelo trato. Entretanto, na presente pesquisa, nenhum desses efeitos foi constatado de modo a influenciar significativamente o consumo nessa fase.

Considerando que o ganho de peso dos animais pode ser diretamente influenciado pela ingestão e o aproveitamento dos nutrientes da ração, criou-se a expectativa de que o aumento de fibra na ração associada à maior inclusão de FAI pudesse prejudicar os resultados de ganho de peso e a conversão alimentar dos leitões, o que não aconteceu.

Vale ressaltar que para tornar as rações isoenergéticas, à medida que se aumentou a inclusão do FAI, houve a necessidade de incluir óleo de soja, aumentando a porcentagem de gordura da ração. Isso pode ter contribuído para que os resultados de ganho de peso e conversão alimentar dos animais alimentados com maior inclusão do FAI na ração tenham sido semelhantes aos obtidos para o grupo controle. De acordo com Sakomura et al. (2004), a adição de gordura na ração beneficia o ganho de peso e a conversão alimentar, devido aos efeitos extracalórico e extrametabólico das gorduras, que consistem, respectivamente, no aumento da disponibilidade dos nutrientes de outros ingredientes da ração e na melhoria da eficiência energética, pelo aumento da energia líquida da ração, em função do menor incremento calórico das gorduras.

Por sua vez, Pupa (2004) relatou que a inclusão de óleo como fonte de energia na ração, além de aumentar o aporte energético, pode ajudar a melhorar a palatabilidade e propiciar uma melhoria na consistência das rações fareladas. Esses efeitos podem ter favorecido para a manutenção do consumo dos animais que receberam as rações contendo níveis crescentes de inclusão de FAI, uma vez que este ingrediente é farináceo e fibroso, características que podem tornar a ração menos densa e pulverulenta, dificultando o consumo.

No geral, pode-se inferir que os leitões aceitaram bem as rações contendo FAI e conseguiram aproveitar os nutrientes da ração obtendo ganho de peso e conversão alimentar semelhantes aos obtidos com o grupo controle, indicando a viabilidade de inclusão do FAI nessa fase até o nível de $20 \%$.

\section{OCORRÊNCIA DEDIARRÉIA}

As percentagens médias de ocorrência de diarréia, assim com as médias transformadas estão apresentadas na tabela III.

Conforme a análise de regressão o aumento dos níveis de inclusão do FAI nas rações não influenciou significativamente $(p>0,05)$ a ocorrência de diarréia nessa fase. Também não foram observadas diferenças entre a ocorrência de diarréia determinada

Tabela III. Escores fecais e médias de ocorrência de diarréia transformadas (MODT) de leitões no período de 21 aos 42 dias de idade. (Fecal scores and average occurrence of diarrhea transformed (MODT) of piglets from 21 to 42 days of age).

\begin{tabular}{lccccc}
\hline & \multicolumn{6}{c}{ Níveis de inclusão de FAI (\%) } \\
Escore & 0,0 & 5,0 & 10,0 & 15,0 & 20,0 \\
\hline 0 & 62 & 36 & 31 & 44 & 47 \\
1 & 54 & 70 & 78 & 60 & 65 \\
2 & 8 & 19 & 14 & 21 & 13 \\
3 & 2 & 1 & 3 & 1 & 1 \\
& & & & & \\
Observações & 126 & 126 & 126 & 126 & 126 \\
& & & & & \\
Escores (2+3) & 10 & 20 & 17 & 22 & 14 \\
Escores (2+3)\% & 7,93 & 15,88 & 13,50 & 17,48 & 11,11 \\
MODT & 0,20 & 0,36 & 0,36 & 0,37 & 0,27
\end{tabular}

FAI: Farelo de arroz integral; Escores: 0 fezes sólidas; 1 fezes pastosas; 2 fezes líquidas/pastosas e 3 fezes líquidas. Diarréia: $2+3$. 


\section{GOMES, CARVALHO, FREITAS, NEPOMUCENO, ELLERY E RUFINO}

para os diferentes níveis de FAI na ração em relação à observada nos animais alimentados sem adição desse alimento (ração controle).

Quanto aos efeitos da inclusão de alimentos fibrosos na alimentação animal sobre a ocorrência de diarréia tem sido relatado que o aumento da fibra poderia favorecer o aumento desse problema visto que a menor digestibilidade e absorção dos nutrientes pelos animais proporcionaria uma maior disponibilidade de nutrientes para os microrganismos presentes no TGI possibilitando em alguns casos o crescimento populacional de bactérias causadoras de diarréias como a E. coli (Pluske et al., 1996).

Por outro lado, tem sido sugerido que a inclusão de fibra na alimentação após o desmame pode reduzir a incidência e gravidade de diarréia em leitões (Bertschinger et al., 1979), associada a uma redução da disponibilidade de substrato para microrganismos patogênicos.

Os componentes dietéticos da fibra são minimamente digeridos no intestino delgado de suínos, providenciando substrato para a fermentação microbiana benéfica no intestino grosso. O principal produto desta fermentação são os ácidos graxos voláteis (AGV) propionato, butirato e acetato, diminuindo o $\mathrm{pH}$ do cólon, que evita a proliferação excessiva de bactérias indesejáveis (Borges e Ferreira, 2004).

A contribuição calórica destes AGV em suínos tem sido estimada em $5 \%$ a $28 \%$ das exigências em energia de manutenção, dependendo da freqüência do consumo e do nível de fibra na dieta (NRC, 1998).

Ausência de distúrbios gastrointestinais durante o período experimental poderia estar relacionada aos efeitos fisiológicos benéficos da fermentação das fibras no trato gastrointestinal resultantes do seu consumo.

Considerando que não houve diferença significativa na ocorrência de diarréia entre os tratamentos e que as rações experimentais foram todas isonutritivas e que apesar dos teores de fibra em detergente neutro e ácido e a gordura das dietas terem aumentado com a inclusão de FAI, pode-se afirmar que a adição de FAI na ração até o nível de 20,0\% não tem relação com a incidência de diarréia, associada aos efeitos do acréscimo de fibra.

Deste modo, a ocorrência de diarréia (7,93 a 17,48\%) é um percentual esperado para leitões dos 21 a 42 dias de idade e as causas do aparecimento de diarréia nos leitões podem ter sido devido ao estresse relacionado à separação da porca, mudança de ambiente e adaptação à nova ração, que segundo Kelly e King (2001), esses fatores podem provocar alterações morfohistológicas importantes, deixando o leitão mais exposto às perturbações intestinais.

\section{VIABILIDADE ECONÔMICA}

Conforme a análise estatística observouse que o nível de inclusão de farelo de arroz integral não influenciou $(\mathrm{p}>0,05)$ as variáveis de custo médio da ração por quilograma de peso vivo (CR), índice de custo da ração (IC) e índice de eficiência econômica (IEE) (tabela IV).

A análise de regressão para os custos das rações por quilograma de ganho de peso vivo, índice de custo e índice de eficiência econômica, mostrou que estes não foram afetados nesta fase de criação indicando assim, a viabilidade econômica da inclusão do farelo de arroz integral até o nível de $20,0 \%$.

De acordo com Hurtado Nery et al. (2010), a utilização de subprodutos de arroz em substituição ao milho, pode melhorar os resultados econômicos da produção de suínos em zonas produtoras de arroz onde o custo dos subprodutos seja menor ao custo do milho e a disponibilidade destes ingredientes permita substituir total ou parcialmente o milho nas rações para suínos em diversas fases sem afetar os parâmetros zootécnicos e a qualidade do produto entregue ao mercado.

Considerando que o aumento da inclusão de farelo de arroz integral (FAI) nas rações reduziu progressivamente a 
FARELO DE ARROZ INTEGRAL EM RAÇÕES PARA LEITÕES DE 21 A 42 DIAS

Tabela IV. Avaliação dos custos das rações para leitões na fase de creche (21 aos 42 dias) utilizando diferentes níveis de inclusão de farelo de arroz integral (média \pm erro padrão da média). (Evaluation of the feed costs for piglets from 21 to 42 days using different levels of inclusion of rice bran (mean \pm standard error)).

\begin{tabular}{|c|c|c|c|}
\hline $\begin{array}{c}\text { Níveis de inclusão } \\
\text { de } \mathrm{FAl}^{1}(\%)\end{array}$ & $\begin{array}{l}\text { Custo da ração } \\
(\mathrm{R} \$)^{2}\end{array}$ & $\begin{array}{c}\text { Variáveis } \\
\text { Índice de custo } \\
(\%)\end{array}$ & $\begin{array}{c}\text { Índice de eficiência } \\
\text { econômica }(\%)\end{array}$ \\
\hline 0 & $1,98 \pm 0,17$ & $100,55 \pm 9,02$ & $102,95 \pm 7,90$ \\
\hline 5 & $2,00 \pm 0,04$ & $101,58 \pm 2,37$ & $98,72 \pm 2,30$ \\
\hline 10 & $1,97 \pm 0,09$ & $100,00 \pm 4,82$ & $101,24 \pm 5,10$ \\
\hline 15 & $2,11 \pm 0,18$ & $107,06 \pm 9,55$ & $97,00 \pm 7,90$ \\
\hline 20 & $2,12 \pm 0,21$ & $107,38 \pm 11,08$ & $97,30 \pm 8,18$ \\
\hline Média geral & $2,04 \pm 0,03$ & $103,31 \pm 1,61$ & $99,44 \pm 1,15$ \\
\hline ANOVA & NS & NS & NS \\
\hline Regressão & NS & NS & NS \\
\hline CV (\%) & 19,11 & 19,10 & 16,46 \\
\hline $\operatorname{Pr}>\mathrm{F}$ & 0,47 & 0,47 & 0,75 \\
\hline
\end{tabular}

${ }^{1} \mathrm{FAI}$ : Farelo de Arroz Integral; ${ }^{2}$ Custo da ração por quilograma de ganho de peso vivo dos leitões; NS: Não significativo $(p>0,05)$ pelo teste $F$; CV: Coeficiente de variação.

quantidade de milho e parte do farelo de soja na composição das rações e que o desempenho dos leitões alimentados com $20,0 \%$ de inclusão do FAI não diferiram significativamente ao obtido para o grupo controle, e que este nível também não afetou a ocorrência de diarréia, além de ser economicamente viável, pode-se recomendar a inclusão de até $20,0 \%$ de FAI em rações para leitões na fase de creche ( 21 a 42 dias de idade).

\section{BIBLIOGRAFIA}

Ara, L.V., Owen, A.A., Buitrago, J. y Pineda, G. 1975. Determinación del valor nutritivo y del nivel optimo de utilización de la harina de arroz en dietas para cerdos. Rev Inst Colomb Agrop, 10: 127-137.

Barbin, D. 2003. Planejamento e análise estatística de experimentos agropecuários. Midas. Arapongas. $194 \mathrm{pp}$.

Bedford, M.R. 2000. Exogenous enzymes in monogastric nutrition: their current value and future benefits. Anim Feed Sci Tech, 86: 1-13. Bellaver, C., Fialho, E.T., Protas, J.F.S. e Gomes,

\section{CONCLUSÕES}

Concluiu-se que o farelo de arroz integral (FAI) pode ser utilizado, até o nível de $20 \%$ de inclusão nas rações de leitões durante o período de creche (21 a 42 dias de idade), sem que haja o comprometimento no desempenho zootécnico, na ocorrência de diarréia dos leitões e nos índices de viabilidade econômica.

P.C. 1985. Radícula de malte na alimentação de suínos em crescimento e terminação. Pesqui Agropecu Bras, 20: 969-74.

Bertol, T.M., Nicolaiewsky, S., Penz Jr., A.M. e Prates, E.R. 1990. Farelo de arroz integral na alimentação de suínos em crescimento e terminação I. Fonte energética. Rev Soc Bras Zootecn, 19: 83-89.

Bertschinger, H.U., Eggenberger, E., Jucker, H. and Pfirter, H.P. 1979. Evaluation of low nutrient, high fiber diets for the prevention of porcine Escherichia coli enterotoxaemia. Vet 


\section{GOMES, CARVALHO, FREITAS, NEPOMUCENO, ELLERYE RUFINO}

Microbiol, 3: 281-290.

Borges, F.M.O e Ferreira, W.M. 2004. Princípios nutritivos e exigências nutricionais de cães e gatos: parte I Energia, proteína, carboidratos e lipídeos. UFLA/FAEPE. Lavras.

Brooks, C.C. and Lumanta, I.G. 1975. Rice bran composition and digestibility by the pig. J Anim Sci, 41: 308-317.

Campabadal, C., Creswell, D., Wallace, M.D. and Combs, G.E. 1976. Nutritional value of the rice bran for pigs. Trop Agr, 53: 141-150.

Campos, R.M., Ludke, J.V. e Terra, N.N. 2002. Farelo de arroz integral e farinha de mandioca integral na dieta de suínos e o efeito na carcaça e no pernil. I Congresso Latino Americano de Suinocultura. Anais... Foz do Iguaçu-PR. pp. 239-240.

Costa, P.T. 2001. O arroz na alimentação animal. Simpósio sobre Ingredientes na Alimentação Animal. Anais... Campinas, SP. pp. 77-84.

Ferreira, W.M. 1994. Os componentes da parede celular vegetal na nutrição de não-ruminantes. Reunião Anual da Sociedade Brasileira de Zootecnia, 31. Simpósio Internacional de Produção de Não-ruminante. Anais... EDUEM. Maringá. pp. 85-113.

Fialho, E.T., Barbosa, O., Ferreira, A.S., Gomes, P.C. e Girotto, A.F. 1992. Utilização da cevada suplementada com óleo de soja para suínos em crescimento e terminação. Pesqui Agropecu Bras, 27: 1467-1475.

Hannas, M.I. 1999. Aspectos fisiológicos e a produção de suínos em clima quente. Ambiência e qualidade na produção industrial de suínos. FEALQ. Piracicaba. 33 pp.

Hurtado Nery, V.L., Soares, R.T.R.N e Chiquieri, J. 2010. Desempenho e características de carcaça de suínos em terminação alimentados com rações contendo subprodutos de arroz. Zootec Trop, 28: 43-49.

Kelly, D. and King, T.P. 2001. Digestive physiology and development in pigs. In: Varley, M.A., Wiseman, J. (Eds.). The weaner pig: nutrition and manegement. CABI Publishing. Nothingham. pp.179-206.

Kyriazakis, I. and Emmans, G.C. 1995. The voluntary feed intake of pigs given feeds based on wheat bran, dried citrus pulp and grass meal, in relation to measurements of feed bulk. Brit $J$ Nutr, 73: 191-207.
Le Goff, G., Van Milgen, J. and Noblet, J. 2002. Influence of dietary fiber on digestive utilization and rate of passage in growing pigs, finishing pigs and adult sows. Anim Sci, 74: 503-515.

Lemos, M.R.B. e Soares, L.A.S. 1999. Farelo de arroz: um subproduto em estudo. Revista Óleos e Grãos, nov/dez: 40-47.

Lima, G.J.M.M., Martins, R.R., Zanotto, D.L. e Brum, P.A.R. de. 2000. Composição química e valores de energia de subprodutos do beneficiamento de arroz. EMBRAPA-CNPSA. Concórdia, SC. Embrapa Suínos e Aves. Comunicado Técnico, 244. 2 pp.

Luchesi, J.B. e Justino, E. 2003. Matérias-primas alternativas na alimentação de frangos de corte e matrizes. Conferência APINCO de Ciência e Tecnologia Avícolas. Anais.... Campinas: FACTA. pp. 137-167.

Miyada, V.S., Lavorenti, A., Luvizotto, J.M., Packer, I.U. e Menten, J.F.M. 1987. Farelo de arroz integral na alimentação de suínos em crescimento-acabamento. Reunião Anual da Sociedade Brasileira de Zootecnia, 24. Anais... SBZ. Brasília.

NRC. 1998. National Research Council. Nutrient requirements of swine. $10^{a}$ ed. National Academy of Sciences. Washington, DC. 189 pp.

Nicolaiewsky, S., D'Agostin, J., Penz Jr., A.M. e Bertol, T.M. 1989. Avaliação do farelo de arroz integral como fonte alternativa de fósforo em rações para suínos em crescimento e terminação. Rev Soc Bras Zootecn, 18: 260-266.

Pluske, J.R., Siba, O.M., Pethick, D.W., Durmic, Z., Mullan, B.P. and Hampson, D.J. 1996. The incidence of swine dysentery in pigs can be reduced by feeding diets that limit the amount of fermentable substrate entering the large intestine. J Nutr, 126: 2920-2933.

Pupa, J.M.R. 2004. Óleos e gorduras na alimentação de aves e suínos. Revista Eletrônica Nutritime, 1: 69-73, julho/agosto. <http://www.nutritime. com.br/arquivos_internos/artigos/009V1N1P69_ 73_JUL2004.pdf> (18/08/10).

Ramonet, Y., Meunier-Salaün, M.C. and Doumand, J.Y. 1999. High fiber diets in pregnant sows: digestive utilization and effects on the behavior of the animals. J Anim Sci, 77: 591-599.

Rostagno, H.S., Albino, L.F.T., Donzele, J.L., Gomes, P.C., Oliveira, R.F., Lopes, D.C., Ferreira, A.S. e Barreto, S.L.T. 2005. Tabelas brasileiras

Archivos de zootecnia vol. 61, núm. 233, p. 138. 


\section{FARELO DE ARROZ INTEGRAL EM RAÇÕES PARA LEITÕES DE 21 A 42 DIAS}

para aves e suínos: Composição de alimentos e exigências nutricionais. $2^{a}$ ed. UFV. Viçosa, MG. v.1. 186 pp.

Sakomura, N.K., Longo, F.A., Rabello, C.B., Watanabe, K., Pelícia, K. e Freitas, E.R. 2004. Efeito do nível de energia metabolizável da dieta no desempenho e metabolismo energético de frangos de corte. Rev Bras Zootecn, 33: 17581767.

Schneeman, B.O. 1999. Fiber, inulin and oligofructose: similarities differences. J Nutr, 129: 1424-1427.

Selle, P.H., Ravindran, V., Caldwell, A. and Bryden,
W.L. 2000. Phytate and phytase: consequences for protein utilization. Nutr Res Rev, 13: 255278.

SAS. 2001. Statistical Analysis System. System for Microsoft Windows. Release 8.2. SAS Inst. Cary.

Vassalo, M. 1995. Probióticos em rações para leitões dos 10 aos $30 \mathrm{~kg}$ de peso vivo. Dissertação (Mestrado). Universidade Federal de Lavras. Lavras. $50 \mathrm{pp}$

Zardo, A.O. e Lima, G.J.M.M. 1999. Alimentos para suínos. 12. EMBRAPA-Centro Nacional de Pesquisa de Suínos e Aves. Concórdia. 69 pp. 